\title{
Prevention of Rheumatoid Arthritis: The Very First Steps
}

Several studies have shown that appropriately treating rheumatoid arthritis (RA) during an early "window of opportunity" markedly improves patient short- and longterm outcomes $^{1,2}$. Because treatment of RA is difficult, costly, and not uniformly effective, it is appealing to target susceptible individuals at some recognizable preclinical stage, where interventions could abort RA development. Strategies could then be devised and tested to alter the inappropriate ongoing pathophysiologic processes, and prevent the subsequent development of inflammation, pain, joint damage, disability, and early death. Similar to Philip K. Dick's Minority Report, in which crimes still to be committed are visualized and their "perpetrators" arrested beforehand, will rheumatologists soon be able to see RA coming and prevent it before it becomes clinically manifest?

In the current issue of The Journal ${ }^{3}$, Smolik and colleagues studied unaffected first-degree relatives (FDR) of North American Natives (NAN) with RA from Manitoba, Canada, a group with a very high prevalence of RA. Nevertheless, because of low annual incidence (lower than $0.5 \%$, even in this highly selected population), Smolik, et al lacked statistical power to study the definitive outcome of interest, RA development itself. Rather, they looked at plausible surrogates: the presence of rheumatoid factor (RF), second-generation anticyclic citrullinated peptide antibodies (anti-CCP2), self-reported joint symptoms, and their potential correlation. While RA-associated antibodies are well known to herald RA development ${ }^{4,5}$, this remains unproven for the presence of joint symptoms in the absence of joint inflammation. Using a screening questionnaire, the authors observed that, as a group, FDR reported more joint symptoms than NAN and non-NAN controls. This increase was significant only in the small subset of FDR that were positive for both RF and anti-CCP2. Although testing positive for both RF and anti-CCP2 antibodies yielded a positive likelihood ratio (LR) above 6 to report joint pain, only $3 \%$ of those with joint symptoms were double antibody positive. Moreover, about one-third of the young (mean age $=38$ years) NAN and non-NAN controls self-reported pain in hands and other joints. These results were not unexpected, considering the high prevalence of arthralgia and periarticular symptoms in the general population. At the very least, this report is not very supportive of self-report questionnaires as a component of a primary prevention strategy for RA.

The report also illustrates that to prepare for prevention studies we need a more exhaustive biological classification of RA, a diagnosis currently based mostly on clinical grounds. Clinicians have known for a long time that what we call RA likely consists of a number of different diseases $^{6}$. The use of the more sensitive 2010 classification criteria may even compound the problem by introducing more heterogeneity among patients with early inflammatory arthritis (EIA) classified as $\mathrm{RA}^{7}$. One obvious dividing line within RA is the presence or absence of autoantibodies. There is strong evidence that anti-CCP2-positive and negative RA patients differ in genomic associations, environmental exposure, and their response to specific medications ${ }^{8}$. Logically, preclinical predictors of seropositive and seronegative RA should also differ. But the antibody division of RA may not be as clean as was initially thought. About one-half of EIA patients are RF and/or anti-CCP2 antibody-positive at diagnosis ${ }^{9,10}$. However, in individual patients with EIA, autoantibodies may convert or revert, while conversion appears to be prevented in some patients treated early $9,10,11$. Differences in midterm outcomes between seropositive and seronegative RA also appear blunted by early and intensive treatment ${ }^{10,12}$. A number of more recent RA-associated antibodies, sometimes found in RF and anti-CCP2 negative sera, are also emerging. For example, anti-Sa antibody positivity has low sensitivity but high specificity for RA ${ }^{10,13}$. While anti-CCP2 antibodies were found in 19\% of FDR of NAN patients with RA, no FDR was positive for anti-Sa, although $61 \%$ of NAN RA expressed anti-Sa ${ }^{14}$. This suggests that finding anti-Sa in an asymptomatic individual might indicate a highly committed status suggestive of impending RA. New antibodies to citrullinated ${ }^{15}$ and homocitrullinated (or carbamylated) antigens are also frequently present in patients without RF or anti-CCP2 ${ }^{16}$. The pathogenic pathways leading to the production of these antibodies targeting antigens produced under very different

See Joint symptoms in RA, page 818

Personal non-commercial use only. The Journal of Rheumatology Copyright (c) 2013. All rights reserved. 
physiological conditions are likely different ${ }^{16}$. Obviously, the relevance of the current antibody classification of RA needs further clarification.

We suggest one needs to go beyond autoantibodies to dissect preclinical RA. As synovia from asymptomatic individuals will remain mostly inaccessible, we must assume that biomarkers identified in peripheral blood adequately represent the rheumatoid processes in tissues. Detailed molecular characterization of biomarkers in blood of early and very early RA and EIA patients will be required to define discrete pathogenic subsets. This approach should identify more homogeneous patient subgroups as well as biomarkers already present at some point before symptom onset. Measures of levels of inflammation markers and of multiple cytokines ${ }^{17}$ are already promising, at least as signs of impending onset of clinical disease, although they may be early consequences rather than villains in the preclinical RA processes. We know that environmental exposures (e.g., tobacco smoke, pneumoconiosis) facilitate, speed up, or amplify RA development and severity. As a consequence, in combination with stable genomic DNA markers such as HLA-DR alleles, environmentally modifiable biomarkers merit strong consideration. Recent technological advances now allow the determination of epigenetic modifications of DNA in peripheral blood cells ${ }^{18,19}$, as well as the use of RNA-based assays to define expression patterns of a large variety of genes. Like autoantibodies, these more recent potential biomarkers also need to be studied prospectively in large cohorts of asymptomatic individuals, some of whom will eventually develop RA, before their use in prevention strategies should be contemplated.

One must also consider the difficulties of prevention strategies dealing with low-incidence disease. Ideally, biomarkers should be detectable from a few months to a few years before RA development to facilitate testing of prevention strategies. Similarly, biomarkers with high positive LR are required. Even a pre-RA marker found to be 99\% specific and 99\% sensitive (positive LR of 99) would only raise the post-test probabilities for RA to less than $30 \%$ when applied to the general population. A set of complementary biomarkers will thus be needed to obtain sufficient predictive power. As multiple pathogenic pathways likely lead to chronic arthritis, any potential biomarker will inevitably have low sensitivity for RA as a whole. Therefore, high specificity will be required to give biomarkers positive LR sufficient to be clinically useful. Optimal combinations and sequences of use of biomarkers need to be defined before submitting still asymptomatic patients to potentially toxic preventive interventions.

This brings us to the social acceptability of screening for preclinical RA. For example, large prevention programs exist for uterine cervix cancer, with a lifetime incidence close to that of RA in women. Because of high rates of false positives and significant morbidity associated with the existing programs, screening strategies are being rationalized $^{20}$. Would such an effort be acceptable to prevent RA, often misperceived as a "mild" disease by decision makers? What would be the effects of screening positive for preclinical RA in the absence of proven preventive treatments? How much toxicity would be acceptable for a partially effective preventive treatment? The answers would be more positive if changes in environmental exposures (e.g., tobacco cessation, diet supplementation), rather than drugs, were shown to be effective to postpone or prevent RA development in susceptible individuals.

Thus, preclinical RA identification remains a distant objective. In the meantime, what can we do now to help individuals developing RA and EIA? We can make sure that current effective treatments are provided earlier and more consistently. Early diagnosis and treatment is still not the rule for Canadian individuals developing RA ${ }^{21}$. We are still failing to identify most patients early enough, and many of the diagnosed ones do not get optimal treatment. Rheumatologists depend on proper identification and referral by astute PCP to be able to deliver treatment to the right person at the right time. Similar to what is being done with other diseases of interest to rheumatologists ${ }^{22}$, we need structured health programs to strengthen and facilitate collaboration between primary care physicians (PCP) and rheumatologists. We also need to support cohorts of EIA, especially those that combine exemplary clinical data with multiple sources of biomarkers (e.g., serum, DNA, RNA, cells). Careful analysis of these cohorts should reveal reliable biomarkers that may ultimately sound an alarm indicating when to intervene in individuals who remain asymptomatic. After all, implementing RA prevention may well represent the cheapest and most definitive solution to that chronic invalidating and frequently lethal disease.

ARIEL MASETTO, $\mathrm{MD}$,

Department of Rheumatology;

MARIE-CLAUDE BEAULIEU, $\mathrm{MD}$, Department of Family Medicine;

GILLES BOIRE, MD, MSc,

Department of Rheumatology,

Université de Sherbrooke,

Sherbrooke, QC, Canada.

Address correspondence to Dr. Boire;

E-mail: Gilles.Boire@USherbrooke.ca

\section{REFERENCES}

1. van Aken J, Lard LR, le Cessie S, Hazes JM, Breedveld FC, Huizinga TW. Radiological outcome after four years of early versus delayed treatment strategy in patients with recent onset rheumatoid arthritis. Ann Rheum Dis 2004;63:274-9.

2. Rantalaiho V, Korpela M, Laasonen L, Kautiainen H, Järvenpää S, Hannonen P, et al. Early combination disease-modifying antirheumatic drug therapy and tight disease control improve long-term radiologic outcome in patients with early rheumatoid arthritis: the 11-year results of the Finnish Rheumatoid Arthritis Combination Therapy trial. Arthritis Res Ther 2010;12:R122. 
3. Smolik I, Robinson DB, Bernstein CN, El-Gabalawy HS. First-degree relatives of patients with rheumatoid arthritis exhibit high prevalence of joint symptoms. J Rheumatol 2013;40:818-24.

4. Nielen MM, van Schaardenburg D, Reesink HW, van de Stadt RJ, van der Horst-Bruinsma IE, de Koning MH, et al. Specific autoantibodies precede the symptoms of rheumatoid arthritis: a study of serial measurements in blood donors. Arthritis Rheum 2004;50:380-6.

5. Nielsen SF, Bojesen SE, Schnohr P, Nordestgaard BG. Elevated rheumatoid factor and long term risk of rheumatoid arthritis: a prospective cohort study. BMJ 2012;345:e5244.

6. Pincus T, Callahan LF. How many types of patients meet classification criteria for rheumatoid arthritis? J Rheumatol 1994;21:1385-9.

7. de Hair MJ, Lehmann KA, van de Sande MG, Maijer KI, Gerlag DM, Tak PP. The clinical picture of rheumatoid arthritis according to the 2010 American College of Rheumatology/European League Against Rheumatism criteria: is this still the same disease? Arthritis Rheum 2012;64:389-93.

8. Huizinga TW, Amos CI, van der Helm-van Mil AH, Chen W, van Gaalen FA, Jawaheer D, et al. Refining the complex rheumatoid arthritis phenotype based on specificity of the HLA-DRB1 shared epitope for antibodies to citrullinated proteins. Arthritis Rheum 2005;52:3433-8.

9. Nell-Duxneuner V, Machold K, Stamm T, Eberl G, Heinzl H, Hoefler E, et al. Autoantibody profiling in patients with very early rheumatoid arthritis: a follow-up study. Ann Rheum Dis 2010;69:169-74.

10. Guzian MC, Carrier N, Cossette P, de Brum-Fernandes AJ, Liang P, Ménard HA, et al. Outcomes in recent-onset inflammatory polyarthritis differ according to initial titers, persistence over time, and specificity of the autoantibodies. Arthritis Care Res 2010;62:1624-32.

11. Barra L, Bykerk V, Pope JE, Haraoui BP, Hitchon CA, Thorne JC, et al. Anticitrullinated protein antibodies and rheumatoid factor fluctuate in early inflammatory arthritis and do not predict clinical outcomes. J Rheumatol 2013 Feb 1. [E-pub ahead of print]

12. Lard LR, Boers M, Verhoeven A, Vos K, Visser H, Hazes JM, et al. Early and aggressive treatment of rheumatoid arthritis patients affects the association of HLA class II antigens with progression of joint damage. Arthritis Rheum 2002;46:899-905.
13. Boire G, Cossette P, de Brum-Fernandes AJ, Liang P, Niyonsenga $\mathrm{T}$, Zhou ZJ, et al. Anti-Sa antibodies and antibodies against cyclic citrullinated peptide are not equivalent as predictors of severe outcomes in patients with recent-onset polyarthritis. Arthritis Res Ther 2005;7:R592-603.

14. Ioan-Facsinay A, Willemze A, Robinson DB, Peschken CA, Markland J, van der Woude D, et al. Marked differences in fine specificity and isotype usage of the anti-citrullinated protein antibody in health and disease. Arthritis Rheum 2008;58:3000-8.

15. Hansson M, Mathsson L, Schlederer T, Israelsson L, Matsson $P$, Nogueira L, et al. Validation of a multiplex chip-based assay for the detection of autoantibodies against citrullinated peptides. Arthritis Res Ther 2012;14:R201.

16. Shia J, Knevela R, Suwannalaia P, van der Lindena MP, Janssen GMC, van Veelenb PA, et al. Autoantibodies recognizing carbamylated proteins are present in sera of patients with rheumatoid arthritis and predict joint damage. PNAS 2011;108: 17372-7.

17. Deane KD, O’Donnell CI, Hueber W, Majka DS, Lazar AA, Derber LA, et al. The number of elevated cytokines and chemokines in preclinical seropositive rheumatoid arthritis predicts time to diagnosis in an age-dependent manner. Arthritis Rheum 2010;62:3161-72.

18. Liu Y, Aryee MJ, Padyukov L, Fallin MD, Hesselberg E, Runarsson A, et al. Epigenome-wide association data implicate DNA methylation as an intermediary of genetic risk in rheumatoid arthritis. Nat Biotechnol 2013;31:142-7.

19. Filková M, Jüngel A, Gay RE, Gay S. MicroRNAs in rheumatoid arthritis: potential role in diagnosis and therapy. BioDrugs 2012;26:131-41.

20. Canadian Task Force on Preventive Health Care. Recommendations on screening for cervical cancer. CMAJ 2013;185:35-45.

21. Tavares R, Pope JE, Tremblay JL, Thorne C, Bykerk VP, Lazovskis $\mathrm{J}$, et al. Time to disease-modifying antirheumatic drug treatment in rheumatoid arthritis and its predictors: a national, multicenter, retrospective cohort. J Rheumatol 2012;39:2088-97.

22. Roux S, Beaulieu M, Beaulieu MC, Cabana F, Boire G. Priming primary care physicians to treat osteoporosis after a fragility fracture: an integrated multidisciplinary approach. J Rheumatol 2013;40:703-11.

J Rheumatol 2013;40:752-4; doi:10.3899/jrheum.130326 